\title{
Youth Mobility Schemes: The Panacea for Ending Free Movement?
}

\begin{abstract}
Free movement has been at the heart of the Brexit debate, with the government grappling between satisfying public and business demands for restrictive and liberal approaches to immigration respectively. In response the government have advocated temporary migration as a potential solution, including an expanded UK-EU Youth Mobility Scheme (YMS) modelled on the current Tier 5 YMS on the assumption that YMS migrants undertake low skilled jobs. Little is known about this visa or the labour market activity of YMS migrants. Drawing on policy analysis alongside survey and interview data from Australian YMS migrants, this paper seeks to bridge some of these knowledge gaps, arguing that an expanded EU YMS will not attract significant EU migrants, and is far from a remedy for free movement ending.
\end{abstract}

Key words: youth mobility scheme, temporary immigration, Brexit, labour market, UK immigration policy

JEL numbers: F22; J08

*This research was supported under the Temporary versus Permanent Migration project (TEMPER). This project received funding from the European Union's Seventh Framework Programme for research, technological development and demonstration under grant agreement no 613488. With thanks to Alexandra Urdea, Martine Huberty and Adam Prangnell who provided research assistance.

\section{Introduction}

The UK labour market has come to be structurally reliant on EU labour to fill shortages in low and mid skilled sectors for over a decade. With 500,000 EU migrants employed in low skilled/low wage industries in $2017^{\mathrm{i}}$, the prospect of ending free movement raises major questions as to how these shortages will be filled. Expanding temporary migration programmes, such as the UK's Tier 5 Youth Mobility Scheme (YMS), whilst no panacea appears to be an attractive solution for policymakers to this dilemma. Whilst details on the UK's future immigration system remain ambiguous, the government has proposed an expanded EU-UK wide Youth Mobility Scheme, modelled on the UK's current Tier 5 Youth Mobility Scheme ${ }^{\mathrm{ii}}$, which allows young migrants from selected countries to live and work in the UK for up to two years. The government has proposed such a scheme because 'it is believed most people who come to the UK under a YMS engage in lower skilled work' and therefore the new scheme will 'provide an additional source of labour for the UK labour market' ${ }^{\text {iii }}$.

The UK's Youth Mobility Scheme (previously working holidaymakers scheme) has long been a passage for young migrants to combine tourism whilst working in the UK. This is a middling form of migration that sits on the nexus between tourism and work migration, which has long represented a rite of passage for young people. Tier 5 migrants including YMS migrants remain politically hidden by their association with tourism, and with no employer sponsor requirements for the YMS the labour market activity of this group is largely unknown. With an expanded EU wide YMS being the only current concrete policy proposal, an examination of whether the assumptions surrounding this mobility are accurate is warranted. This paper examines the YMS, including the policy evolution and labour market activity of current YMS migrants to explore whether a EU wide YMS is feasible or even desirable. Drawing on a study of Australian YMS migrants in London, I argue that the YMS is unlikely to attract significant EU migrants to the UK to meet employers' needs. If this scheme is to be 
successful in attracting significant numbers of young EU migrants, various rights under the YMS would need to be expanded.

Methodologically the article is based on three sources. Firstly, policy analysis of relevant government documents combined with findings from an immigration policy index ( $\mathrm{ImPol}$ ) to visualise changes in the YMS over time. Secondly, 75 surveys with Tier 5 Youth Mobility Australian migrants living in London. Thirdly, 20 in depth interviews YMS Australians conducted between April 2015 and May 2016.

\section{Liberal labour market}

The plans to end free movement, and with it a loss of EU labour, has panicked many UK employers and not without reason. The Confederation of British Industry estimates that EU workers make up to 30 per cent of the total workforce in different sectors, that the contribution of EU workers 'will be needed in the future' and that the 'current non-EU immigration system is not a solution for EU nationals ${ }^{\text {iv }}$.

The UK's reliance on EU labour stems from its mode of capitalism, typically regarded as a liberal market economy ${ }^{\mathrm{v}}$ entailing low employment protection, light regulations and a large low-wage sector $^{\mathrm{vi}}$. There is consequently a lack of coordinated wage bargaining arrangements, and firms primarily coordinate their activities via competition market arrangements. As a result, there are incentives for employers to delay costly technological advancements in favour of depending on lowwage labour vii. Declining apprenticeship and training schemes in Britain have further fostered the reliance on importing labour. Coupled with decades of deregulation this has lowered incentives for employers to invest in skills and training for the domestic labour force. As a result, many sectors such as social care, retail and hospitality and construction have come to rely on EU labour to fill labour shortages in key sectors in lieu of a native workforce willing to take up low quality jobs.

\section{Immigration policy: Temporary migration}

Key to the UK labour market being reliant on EU labour is that free movement requires no certification and in turn no bureaucracy. This has meant that the UK has enjoyed a pool of flexible EU workers willing to take jobs which the native workforce deem undesirable, and in turn government has had the luxury of foregoing establishing any politically contentious low skilled visas. This is in contrast to the principal work entry channel - Tier 2 - for skilled workers where workers must meet stringent eligibility criterion including salary thresholds of $£ 30,000$ and employers must undertake lengthy, bureaucratic and expensive sponsorship requirements. For employers seeking highly skilled workers with long-term contracts, such an endeavour is worth the pain. However, low or mid skilled sectors where vacancies cannot fulfil the proposed stringent Tier 2 requirements and job forecasting is more short term have different needs, above all flexible workers willing to undertake low quality, time limited jobs.

Yet whilst the labour market demands a stock of flexible migrant labour, the public has expressed a preference for migration to be reduced. Temporary migration is seen as the in-between solution

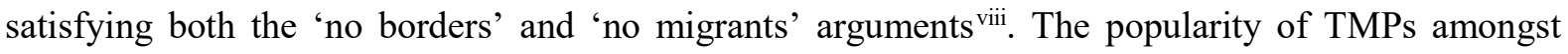
policymakers stems from the so-called 'triple-win' outcomes: the host country can meet labour market demands whilst appeasing electoral concerns over permanent settlement; the sending country benefits from both remittances and skills transfer/brain gain from migrants acquiring skills in the destination state and transferring these skills on return; and the migrants themselves benefit by a mechanism which provides people from low-income countries with better access to labour markets in highincome states.. As a result, the UK government has been endorsing temporary migration since the 
introduction of the net migration target in 2010, although there is no explicit or official commitment to temporary migration.

Whilst policymakers advocate for temporary migration, TMPs have rightly been critiqued for being potentially exploitative.. Australia's equivalent YMS - working holidaymakers scheme - sets a precedent for the dangers of exploitation of young temporary migrants, including 'gross underpayment of wages, excessive hours of work, sexual and other forms of harassment and substandard living conditions' ${ }^{\text {ix }}$. Such exploitation has been aggravated by new policy terms that nudge WHMs into specific regional low skilled sectors in return for an entitlement to work for a second year in Australia ${ }^{\mathrm{x}}$. More generally, policies that discourage long-term settlement provide few incentives to integrate, leading to poor community cohesion.

Despite the dangers of rights violations under badly regulated TMPs, the Coalition government (20102015) and the Conservative administrations (2015-2019) have favoured a migration system underpinned by temporariness. This is in pursuant with the net migration target put forward by the Conservative Party to reduce immigration to 'sustainable levels'. Crucially third country nationals who are present for less than 12 months do not count in the net migration figures. A major component of the Conservative governments' policy has been to ensure that economic immigration is an exclusively temporary phenomenon, or to 'break the link' between permanent and temporary migration as epitomised by Prime Minister May when Home Secretary in 2010:

It is too easy, at the moment, to move from temporary residence to permanent settlement...Working in Britain for a short period should not give someone the right to settle in Britain...Settling in Britain should be a cherished right, not an automatic add on to a temporary way in ${ }^{x i}$.

This appears to be a 'point of principle for the Conservatives' xii, with former Prime Minister Cameron stating in April 2011 'It cannot be right that people coming to fill short-term skills gaps can stay long term' ${ }^{\text {xiii. }}$.

Whilst at the time of writing the future immigration system post Brexit is unclear, the government published two White Papers in 2018 that signalled the direction of future policy. In recognition of the short-term recruitment challenges employers are facing when free movement ends, the government have proposed a temporary strictly time limited 12-month visa for all skill levels from 'low risk countries' with no route to permanency or right to bring family. This is proposed as a transitory measure that will be regularly reviewed, subject to numerical caps, tightening criteria and possibly closure if economic conditions warrant it ${ }^{\text {xiv }}$. The government may also re-establish the Seasonal Agricultural Workers Scheme to fill labour market demands in agriculture and horticulture, and the government are currently running a small-scale pilot scheme to this effect.

Yet the key consistent proposal in both White Papers is the establishment of an EU wide Youth Mobility Scheme. The government have proposed an EU-EU YMS as part of their Mobility Framework 'to ensure that young people can continue to enjoy the social, cultural and educational benefits of living in the EU and the $\mathrm{UK}^{{ }^{\mathrm{xv}}}$. The government intend to design the scheme in broadly the same way as the existing YMS 'taking account of EU specificities' with the government claiming that 'it will provide an additional source of labour for the UK labour market' ${ }^{\text {'xi. }}$. This warrants an examination of the current YMS and how this visa has evolved from tourist mobility to labour migration.

\section{Policy Evolution: Working holidaymakers and Youth Mobility}


The existing UK Youth Mobility Scheme (YMS), formerly known as the working holidaymakers scheme, (WHM) is historically one of the longest running youth schemes globally. Concordant with post-war concerns to preserve ties with the Commonwealth - ironically due to Britain's new dominant geopolitical alliance with the European Economic Community ${ }^{x v i i}$ - the Commonwealth project was at the heart of the original Working Holiday Makers scheme. It was designed principally as a cultural exchange programme for young Commonwealth citizens and thus purely intended for tourism and cultural exchange. However, the scheme has been transformed over the years from the perspective of policymakers from Commonwealth tourist mobility and cultural exchange to a labour market route.

Throughout the history of the scheme applicants must always retain entry clearance before being admitted including obtaining a biometric residence permit. Moreover, both the previous WHM and the current YMS work on a reciprocal quota basis with each participating country being allocated a number of visas based on reciprocal agreements. There were 41,652 YMS visa granted in the year to September 2017, down one per cent on the previous year ${ }^{\text {xviii }}$.

Whilst the broad design of the scheme has remained consistent - allowing participants to stay in the UK for up to two years, with permission to work and little post entry controls - the eligibility criterion and rights attached to this visa have changed over the years, as can be seen from the graph below. The graph is derived from the Immigration Policy Index ( $\mathrm{ImPol}$ ), which measures policy restrictiveness across time and different visas on a basic ordinal scale. The coding is derived from original legal sources in this case the immigration rules ${ }^{\mathrm{xix}}$.

\section{GRAPH ONE ABOUT HERE: ELIGIBILITY VERSUS RIGHTS YSM}

For the duration of the 1990s, the eligibility criterion and rights attached to the visa remained consistent. The 2000s New Labour governments significantly liberalised the WHM by allowing participants to transit to other visas in country, increasing the age eligibility from 18-27 to 18-30, whilst also liberalising the type of work that could be undertaken. The liberalising changes made to the Working Holiday Makers Scheme were principally made to 'provide a pool of flexible labour that can help alleviate recruitment difficulties faced by UK employers' ${ }^{\prime}$. However, in 2005 the scheme was restricted, with the old criterion being reinstated.

Following the introduction of the points-based system (PBS), in 2008 the Working Holidaymakers Scheme was consolidated with other temporary routes (such as Au Pair visa) and was renamed the Youth Mobility Scheme (YMS), subsided under Tier 5 of the PBS which is specifically for temporary migration. The age criterion was raised again from 28 to 30 and a maintenance requirement was attached to this visa for the first time. Yet the most significant change has been the addition of nonCommonwealth nationals as participants, moving the scheme away from Commonwealth facilitated mobility.

The YMS is currently restricted to eight participating countries, which have a special reciprocal agreement with the UK.. These include: Australia, Canada, Japan, Monaco, New Zealand, Hong Kong, Republic of Korea and Taiwan. Each participating country is prescribed an annual allocation of total YMS visas, based on reciprocal agreements with Australians allocated 70 per cent of the total YMS visas available in 2016. As was previously the case under the WHM scheme, those with British overseas, British overseas territories or British national (overseas) citizenships' can also apply.

. The YMS is a one-shot visa meaning that applicants must not previously have entered or spent time in the UK on a Working Holiday Visa, or a Tier 5 YMS visa. The current YMS visa gives 24 months leave to remain and limited working restrictions ${ }^{\mathrm{xxi}}$. Participants cannot extend their stay, cannot access public funds and cannot bring family. 
There are two fundamental differences in the YMS visa in contrast to all other UK visas. Firstly, the YMS is age specific, and secondly the visa has no sponsorship requirements. In the case of youth mobility schemes, temporal eligibility - referring to the biological age restrictions for these visas (aged 18-30) - confers particular life stages as desirable bio-political characteristics of migrants where youth is prized ${ }^{\mathrm{xxii}}$. Young migrants are then constructed 'as desirable migrants of the neoliberal state, representing labour capacity without the 'social burden' associated with being elderly or having dependent children' ${ }^{\text {xxiii }}$.

The second crucial difference in the YMS visa in contrast to all other visas in the UK system is that it does not require a job offer, employer sponsorship or stringent Tier 2 eligibility requirements. Employers can therefore easily hire YMS migrants without bureaucratic processes or the need to conduct a resident labour market test to ensure no resident can fill a vacancy. In this sense, the YMS visa is the most liberal in the UK immigration system. At the same time, the lack of certification criterion means there is a lack of data available regarding the labour market activity of YMS migrants, or indeed their distributional spread across the country.

\section{Youth Mobility Migrants: Australians in London}

Whilst YMS or working holidaymakers globally are far from a homogenous group, there are a number of characteristics that form the typical profile of a working holidaymaker: young, middle class, and often highly educated. The YMS is often undertaken as a rite of passage ${ }^{\text {xxiv }}$ for the inbetween life stages for example between higher education and professional careers. Between visa (including required savings and the NHS surcharge) and travel costs coupled with savings needed to safeguard against initial unemployment, undertaking a prolonged overseas experience, especially in London, is an expensive endeavour.

The research consisted of a sample of 75 YMS Australians predominantly living in London. This is a non-representative and a small sample but nonetheless our results provide a snapshot of the activity of YMS Australians residing in London. It is important to note that the labour market activity in other towns/cities or other nationalities on YMS may be vastly different yet with no sponsorship requirements there is no data available on where YMS migrants reside in the UK, why they migrate to specific locations or what jobs they undertake. For example, in a study of Canadian YMS migrants in Scotland, the majority of respondents were working in hospitality, with many living and working in the same hostels ${ }^{\mathrm{xxv}}$. In another study involving WHM New Zealanders in Britain (mostly London) the type of work undertaken by participants 'varied enormously, from traditional travellers' jobs (such as nanny and bar work), middle income professional jobs like nursing or teaching, to high-powered professional career jobs (in finance, banking)' ${ }^{\text {xxvi }}$.

Participants were selected via snowball sampling with the assistance of an expatriate group (Aussies in London) set up specifically for young Australians in London ${ }^{\text {xxvii. }}$ We conducted a closed survey with 75 migrants at various events set up by the group, and twenty of these individuals self-selected for in-depth interviews conducted at a later time in various locations across London between April 2016 and May 2017. The survey sample consisted of 32 male respondents and 43 female respondents, with the majority originating from New South Wales ( 40 per cent), followed by Victoria ( 25 per cent) and Western Australia (13 per cent). Interviews were coded manually using a basic coding framework to identify key themes from the interviews including motivations to migrate, integration themes, socialisation, and labour market relations.

From the outset it needs to be stressed that Australian migrants residing in the UK are somewhat unique in comparison to other nationalities due to the deep history of migration and colonial ties 
between nations. The UK has long been the preferred destination for Australians looking to permanently emigrate, accounting for 20.9 per cent of Australian emigrants in the period 1996 and $2006^{\text {xxviii. }}$

\section{Labour market activity: assumptions and realities}

While temporary migrants have typically being concentrated in low skilled sectors and often face prolonged periods of unemployment ${ }^{\mathrm{xxix}}$, a striking finding among our respondents was that the majority had no difficulties in acquiring a job and were working in high and mid skilled professional occupations. The latter finding chimes with other research, which has found that a significant number of WHM Antipodean migrants in London work in middleincome occupations in the health, education and media industries ${ }^{\mathrm{xxx}}$. The institutional and structural mechanisms in place via recruitment channels and commercial agencies specifically targeted at young Australians (and especially in teaching sectors) also facilitate and streamline YMS Australians into particular social circuits and jobs. The findings demonstrate that YMS Australians have a positive and inclusive experience in the UK labour market in stark contrast to many other temporary migrants. This stems from employers' apparent preferences for temporally flexible, ultra-mobile workers arguably coupled with proficient English, the aesthetic labour characteristic of youth, and the acceptable trade-off of precariousness young Australians accept in return for the flexible working arrangements to suit their travel plans. Importantly, race and language were important factors shaping YMS Australians positive experience, and whiteness, as a 'passport for privilege' ${ }^{\mathrm{xxxi}}$ undoubtedly shapes these experiences. Different ethnicities, ethno-culture nationalities and visa statuses construct differing preferences for jobs, forging a hierarchy of desirability underpinned by economic worth and ethno-cultural privileging. This hierarchy is key to understanding the Australian YMS experience.

While the sample were largely highly skilled - defined as possessing tertiary education - over half did not try to get their qualifications recognised in the UK (40), and of those who did 28 had no difficulties getting qualifications recognised. The majority of our respondents used a recruitment company before leaving Australia to secure employment before arrival., The majority of respondents were, unsurprisingly given their temporary status, working on time-limited work contracts, with the majority on fixed term contracts lasting less than 12 months. YMS Australians were overall content with their precarious contracts; only 24 respondents wanted a more permanent or secure job in the UK, and 36 respondents stated they were working in either their ideal job or sector.

The young Australians in our sample were both highly skilled with 46 respondents possessing a bachelor degree or higher, and the majority were working high skilled professional jobs. In contrast, no respondents were working in elementary occupations. Twenty-five respondents were working in the teaching professions, principally as substitute teachers. However, this may be due to a sampling bias as we used a snowball sampling strategy and/or that the expatriate group may be overrepresented by those in teaching professions due to friendship networks utilising the same service. Young Australians find it easy to acquire employment, with 63 respondents in employment and 54 respondents having applied for between zero and five jobs in total.

The majority of respondents had no trouble in gaining employment in the UK (55), zero respondents had experienced discrimination, and over half of respondents said that they have never been in the 
position of looking for work in the UK (39). Of those that had difficulties in gaining employment, the two key issues were administrative loop holes with acquiring national insurance numbers, and the time-limited YMS visa itself dissuading employers. YMS Australians are undeterred by precarious contracts because mobility is principally for leisure and therefore their primary consideration is shortterm financial gain with maximum employment flexibility:

[My friend] she gets paid peanuts but with 10 months on her visa to go she'd rather stick to that as she doesn't think another employer will pick her up... a lot of employers want to see that longer term visas (Female, 25)

While all participants spoke about being motivated to migrate as a rite of passage and/or time to selfexplore before "growing up", for some - with London's global reputation - it also served as a way to build their career prospects. Just under a third of the sample cited work experience and improving career prospects as their primary motivation to migrate to Britain, and 50 respondents thought their work experience would aid their career when returning to Australia. Broadly, those in the younger cohort (aged 18-24) migrated purely for "play" in contrast to older YMS (aged 25-31) Australians who while seeking a rite of passage also migrate to the UK for work experience and career progression back in their homeland. This in turn highlights the blurriness of this mobility between self-exploration and individualisation and economic calculus:

Essentially there is more of a competitive market, bigger companies involved so it's more competitive and they attract a range of international talent as well, so I guess it's competitive not just in terms of the actual market but also in terms of human resources as well, in terms of other people wanting jobs. So it's quite multicultural in that aspect so I think working with people from different countries - that's value to bring back to Australia in addition to more of the job specific components and being able to work with, yes, bigger budgets, more difficult clients and different scenarios (Male 29)

\section{Motivations to migrate}

Precarious work was an acceptable trade-off for these young migrants for the pull of London in terms of global transport to Europe: 'You just have to work to sustain travel' (Female 25). Sixty five respondents had travelled to destinations in Europe during their stay in Britain, and 42 respondents cited travelling in Europe specifically as their main motivation to migrate. It is precisely the integration of long-term leisure travel with employment, which 'extends both the temporal and experiential dimensions of the overseas experience beyond what is commonly understood as tourism' ${ }^{\text {xxxii }}$. Yet this mobility is undoubtedly motivated at least in part, if not primarily, for tourism in a broad sense.

What was striking amongst respondents, was that the decision to migrate was not about Britain per se, but London specifically and crucially the ease of travelling to Europe: In terms of application for leaving Perth I was purely invested in London in hearing about those opportunities... I didn't have any interest in any other city to be honest (Male 27). This is not unique to young Australians of course, nor is there anything unique about London to other global cities. Nonetheless, one of the key pulls of London for these young migrants then is its central position in terms of global transport to Europe and more generally hubs of communication flows.

The attraction of London is within its internationally connected cultural and social institutions, and its cosmopolitan environment. Interviewees spoke about being enlightened by living in London and experiencing 'super diversity' xxxiii, especially from those who grew up in rural towns in Australia: 
People said London is a multicultural city. And you're like of course it is, it's one of the biggest cities and it's in Europe. But in my head I didn't expect it to be this multicultural. In my head I'd painted a picture of a normal day in London, and I wouldn't have imagined so many varieties of culture, especially coming from Australia where we are multicultural but we're still pretty damn white. So for example we'd never seen an Orthodox Jew before! It's really broadened our ideas of religion and cultures (Female 28, Male 26)

The majority had never left London and had left only to make short visits within Europe. This reinforces that, in our sample at least, YMS Australians, are drawn to London and the ease of travel to Europe specifically, as opposed to the UK generally. YMS Australians chose to migrate to the UK specifically for three key reasons: 42 respondents said London offers better travel opportunities, 25 respondents cited common language making the UK the ideal destination, and 20 respondents said the YMS visa itself is easy to acquire. It is possible that London is particularly attractive for YMS Australians specifically, yet the overall Australian population in the UK is disproportionately resident in London in contrast to the rest of the UK (53 per cent) ${ }^{\text {xxxiv }}$.

Essentially London offers YMS Australians easy travel connections to Europe whilst at the same time being an English-speaking nation with similar cultural, political and social institutions to Australia. Moreover, the UK generally is a familiar place for YMS Australians with almost half our respondents having previously visited the UK. Crucially the UK offers YMS Australians familiar networks due to either extended family or other Australians being resident in the UK, with most of our sample (59) knowing another Australian living in London before arriving. London offers these young migrants who are usually experiencing migration for the first time - both a level of familiarity and excitement.

\section{Conclusion}

Post Brexit immigration policy is currently unclear and may ultimately be determined by any trade deals the UK agree with reciprocal countries. Nonetheless, the loss of EU labour is likely to impact on particular sectors, especially low (or fundamental) skilled-based sectors. One of the government's concrete proposals is to establish an EU wide YMS on the belief that YMS migrants undertake low skilled jobs. With no certification requirements on the current YMS visa, there is relatively little known about YMS migrants. Drawing on policy analysis alongside survey and interview data from Australian YMS migrants, this paper has sought to bridge some of the knowledge gaps as to the labour market activity and the motivations to migrate of YMS migrants.

Our findings suggest that the assumptions surrounding the sectoral and skill distribution of YMS migrants as dominated in low-skilled sectors is potentially inaccurate. Whilst our sample was small and non-representative, the majority of Australian YMS migrants were working in high skilled professions. This calls into question whether the proposal for an EU wide YMS would necessarily alleviate post-Brexit residual labour shortages in low and mid skilled sectors. Whilst it is of course possible that other YMS migrants take up low skilled jobs in other UK regions, the abundance of middle or high skilled jobs in London, albeit precarious, provide little incentive for YMS migrants to undertake low skilled jobs.

However, Australians are in many ways a unique and privileged migrant group in the UK's immigration hierarchy; they are not necessarily reflective of wider YMS migrants profile or experience, nor can their relative satisfaction with the YMS be assumed for other migrant groups. Considering many EU nationals, including underemployed highly skilled individuals, work in low or mid skilled professions in the UK due to wage differentials from their sending country (especially from Central and Eastern Europe), it is possible that the proposed two-year visa may be attractive to 
some, and therefore substitute for some residual low skilled shortages. This is especially because YMS visas allow for a longer residence than the proposed 12-month low skilled visa, with otherwise little difference in labour market restrictions. The proposed YMS may establish reciprocal agreements with non-EU countries, described as 'other key players', and this will make a substantial difference to the take-up of the scheme as it may offer a route for citizens of other countries who previously faced restrictions working in the UK. Key to the attractiveness of the YMS (especially in contrast to the 12month low skilled visa) will be whether, like the Australian government, the UK government choose to include a provision to channel YMS workers into specific areas of low skilled labour shortages. Given that the government will need to establish reciprocal agreements with individual countries, exactly which countries will be included and how quotas will be determined will be key to whether the scheme is attractive, whether YMS migrants concentrate in low skilled sectors and thus whether an EU-YMS would fulfil the government's ambition of plugging low skilled labour shortages.

Nonetheless, key to the success and attractiveness of the current YMS visa is that it provides non-EU migrants an opportunity to travel Europe more widely. This is evidently the critical reason why Australian YMS migrants select the UK as their destination of choice. Given that EU citizens can freely travel, work and reside in all Member States, there is little reason to believe that the UK would be attractive for young EU citizens in this respect. A further reason YMS Australian migrants choose the UK is that English is the dominant language allowing migrants to acquire employment and integrate relatively easily. Evidently, this would not be the case for nationalities of the remaining 27 Member States, thus reinforcing that an EU wide YMS would not necessarily be attractive to EU citizens. Of course EU migrants may wish to improve their English language skills by residing in the $\mathrm{UK}$, but whether this alone is significant enough to attract young EU migrants is highly questionable. London as a global super diverse city with its cosmopolitanism and global reputation in many sectors provides a final motivation for YMS Australians to reside in the UK. Yet it is possible that Brexit, and the likely negative economic impact, may detrimentally effect London's reputation in this regard ${ }^{\mathrm{xxx}}$, which raises questions around whether London would remain an attractive destination for young EU migrants. Moreover, labour shortages from free movement ending are likely to hit many parts of the UK outside of London. All things considered, it is unlikely that the YMS visa would be as attractive to young EU migrants as it is with non-EU migrants. There is simply little to offer which EU migrants cannot acquire elsewhere in Europe with no limitations on their residency and opportunities to settle.

More generally, expanding temporary migration routes runs the risk of increasing exploitation and potentially irregular migration. From the employer perspective, especially those in low skilled sectors, the training necessary for many jobs dissuades employers from hiring temporary migrants, in the knowledge that their workers will need to leave (Rolfe and Davies, 2017). At the same time, if the government were to propose certification requirements for YMS migrants in order to nudge and control migrant workers into specific sectors where shortages were rife, this creates the potential for exploitation (as seen in the WHM in Australia see Reilly 2015), and again offers employers little incentive to undergo a heavily bureaucratic and often expensive sponsorship process for workers who will leave within a short period.

The policy evolution of the YMS visa reveals how the numerous administrations have remodelled the visa from a Commonwealth tourism scheme to a labour market route. If the government were to establish this as an EU wide scheme it would need to expand rights in order to make this attractive to EU migrants. This could include reinstating previous rights, such as allowing YMS migrants to transit to another visa whilst remaining in the UK (such as a Tier 2 visa), and providing a route to permanency by allowing the YMS visa time to count towards eligibility for indefinite leave to remain. This is especially pertinent given that our findings suggest that YMS migrants are skilled individuals 
and thus more liberal rights attached to this visa could potentially be in line with the government's aims to boost human capital and attract high skilled migrants ${ }^{\text {xxxvi }}$. Evidently, even providing for a more attractive visa may not be enough to attract EU migrants to a country that is seen to have a reputation for being hostile to immigrants.

${ }^{\text {i }}$ Migration Observatory (2018), Exploiting the Opportunity? Low-Skilled Work Migration
After $\quad$ Brexit. https://migrationobservatory.ox.ac.uk/resources/reports/exploiting-the-opportunity-lowskilled-work-migration-after-brexit/

${ }^{\mathrm{ii}}$ HM Government (2018a), The Future Relationship between the UK and the European Union, London, HM Government. Available from: https://assets.publishing.service.gov.uk/government/uploads/system/uploads/attachment_data /file/725288/The future relationship between the United_Kingdom and the European_Un ion.pdf; HM Government (2018b), The UK's furture skill-based immigration system. Available

from: https://assets.publishing.service.gov.uk/government/uploads/system/uploads/attachment data /file/766465/The-UKs-future-skills-based-immigration-system-print-ready.pdf

iii Ibid, p.55

${ }^{\text {iv }}$ Confederation of British Industries [CBI] (2018), Open and Controlled: a new approach to immigration after Brexit. Available from: http://www.cbi.org.uk/index.cfm/ api/render/file/?method=inline\&fileID=4232B592-ACCC40DB-9338BA0A97198435, pp: 3-4

${ }^{v}$ Soskice, D.W. (2001), Varieties of capitalism: The institutional foundations of comparative advantage, Oxford, Oxford University Press.

${ }^{v i}$ Afonso, A. and Devitt, C. (2018), 'To be less dependent on immigration, Britain must change its model of capitalism', LSE: British Politics and Policy. Available from: http://blogs.lse.ac.uk/politicsandpolicy/to-be-less-dependent-on-immigration-britain-mustchange-its-model-of-capitalism/

vii Menz, G. (2008), The political economy of managed migration: Nonstate actors, Europeanization, and the politics of designing migration policies, Oxford, Oxford University Press.

viii Ruhs, M. and Martin, P. (2008), 'Numbers vs. rights: trade-offs and guest worker programs', International Migration Review, 42.,1.,pp. 249-265., p. 260

${ }^{i x}$ Reilly, A. (2015), 'Low-cost labour or cultural exchange? Reforming the Working Holiday visa programme', The Economic and Labour Relations Review, 26.,3, pp.474-489., p. 475

${ }^{x}$ Ibid

${ }^{x i}$ May, T. (2010), 'Immigration: Home Secretary's speech of 5 November 2010'. Available from: https://www.gov.uk/government/speeches/immigration-home- secretarys-speech-of-5november- 2010

xii Cavanagh, M. (2011), Guest workers: Settlement, temporary economic migration and a critique of the government's plans. London: IPPR.

xiii Cameron, D. (2011), 'Prime Minister's speech on immigration, 10 October'. Available from: https://www.gov.uk/government/speeches/prime-ministers-speech-on- immigration 
xiv Ibid, p.17

${ }^{x v}$ Ibid, p.55

xvi Ibid

xvii Consterdine, E., (2017), 'Community versus commonwealth: reappraising the 1971 Immigration Act', Immigrants \& Minorities, 35.,1., pp.1-20.

xviii Home Office (2017), Why do people come to the UK? Available from: https://www.gov.uk/government/publications/immigration-statistics-july-to-september2017/why-do-people-come-to-the-uk-2-to-work

${ }^{x i x}$ For further methodological details see Consterdine, E. and Hampshire, J. (2016), Coding Legal Regimes of Immigration Entry to the EU with a focus on Labour Immigration, Madrid, Temper. Available from: http://www.temperproject.eu/wpcontent/uploads/2016/08/Working-Paper-8.pdf

${ }^{\mathrm{xx}}$ Home Office (2002), Working Holidaymakers Scheme: Consultation Documents, London, Home Office.

${ }^{x x i}$ Applicants cannot work as a professional sportsman or a doctor or dentist unless they can show they qualified in the UK

xxii Robertson, S. (2014), 'Time and temporary migration: The case of temporary graduate workers and working holiday makers in Australia', Journal of Ethnic and Migration Studies, 40.,12., pp.1915-1933., p.1922

xxiii Ibid, p. 1923

xxiv Clarke, N. (2004), 'Mobility, fixity, agency: Australia's working holiday programme', Population, Space and Place, 10.,5., pp.411-420.

${ }^{x x v}$ Rice, K. (2010) 'Working on Holiday': Relationships between Tourism and Work among Young Canadians in Edinburgh', Anthropology in action, 17,1, pp.30-40.

xxvi Wilson, J., Fisher, D. and Moore, K. (2009) 'The OE goes 'home': Cultural aspects of a working holiday experience', Tourist studies, 9(1), 3-21.

${ }^{x x v i i}$ Aussies in London' Facebook group - https://www.facebook.com/AussieInLondon/ . This group was set up to help and support Australians living in London by 'encouraging them to socialize and build their support networks, providing useful and relevant information, and providing a sense of community'.

xxviii Hugo, G. (2008) 'Immigrant settlement outside of Australia's capital cities', Population, Space and Place, 14,6, pp.553-571.

xxix Fleischmann, F. and Dronkers, J. (2010) 'Unemployment among immigrants in European labour markets: an analysis of origin and destination effects', Work, employment and society, 24.,2., pp.337-354.

xxx Conradson, D. and Latham, A. (2005) 'Friendship, networks'

xxxi Andrucki M (2010) 'The visa whiteness machine: transnational motility in post-apartheid

South Africa', Ethnicities 10(3), pp. 358-370.

xxxii Wilson, J., Fisher, D. and Moore, K. (2009), 'The OE goes 'home', p.160

xxxiii Vertovec, S. (2007), 'Super-diversity and its implications', Ethnic and racial studies, 30., 6, pp.1024-1054. 
xxxiv Salt and Miller (2006), 'Foreign Labour in the United Kingdom: Current Patterns and Trends', Labour Market Trends, October, 335-355.

${ }^{x x x v}$ Davies, H. (2017), 'Will London survive as a financial centre after Brexit?', The Guardian, 26 April. Available from: https://www.theguardian.com/business/2017/apr/26/london-financial-centre-brexit-eu-parisfrankfurt-uk

${ }^{x x x v i}$ HM Government (2018b), The UK's furture skill-based immigration system 